\title{
PERMISOS DE CONSTRUCCIÓN
}

\author{
LICETT CAROLINA FREIRE PAREDES 1
}

\section{TUNGURAHUA}

Pag 11-12

\section{Resumen}

En este artículo se realiza un análisis general sobre las variaciones registradas en el periodo 2013-2014 de permisos de construcción en Tungurahua, en cuanto a, tipo de obra y usos, sean residenciales o no residenciales. Se muestra también las preferencias de los constructores por fuentes de financiamiento propias o provenientes de préstamos, los materiales predominantes utilizados en cimientos, estructura, cubierta y paredes de edificaciones y el otorgamiento de permisos por metro cuadrado. En 2014, en la provincia se evidencia incremento del número de permisos con respecto a 2013 de acuerdo a información obtenida de la encuesta de edificaciones del Instituto Nacional de Estadística y Censos - INEC.

\section{Palabras clave:}

Permisos de construcción, tipo de obra, residencial, materiales predominantes, Tungurahua

\section{Abstract}

In this article a general analysis on the variations registered in 2013-2014 period of the construction permits issued in Tungurahua, according to type of building and uses, between residential and non-residential. It also shows builders preferences when they have to decide between using their own financial sources or bank credits, materials used mainly in the foundation, structures, roof and walls of buildings and the permission given by the square meter. In 2014, in the province of Tungurahua, there was registered an increase of permissions granted compared to 2013 according to the information obtained from the survey for buildings of the National Institute of Statistics and Census.(INEC).

\section{Keywords:}

Construction permissions, type of buildings, residential, main materials, Tungurahua.

\section{Introducción}

Dentro del Plan de Ordenamiento Territorial Ambato 2020, en su Art. 147 de la Sección Tercera del Permiso de Edificación indica que un permiso de edificación "es la autorización para desarrollar en un predio o predios, determinadas obras de nueva construcción, reconstrucción, remodelación y/o ampliación...". En el año 2014 Tungurahua ocupa el octavo lugar a nivel nacional con 1.651 permisos que representan el $6,07 \%$ del total.

El presente artículo realiza un análisis general sobre propósitos de construcción, tipo de obra, fuentes de financiamiento y materiales utilizados a nivel nacional y de manera específica en la provincia de Tungurahua, utilizando datos oficiales del INEC de la Encuesta Anual de Edificaciones 2012, 2013 y 2014, basada en los permisos de construcción concedidos por los Gobiernos Autónomos Descentralizados Municipales.

\section{Contenido}

A nivel nacional el otorgamiento de permisos de construcción desde el año 2009 ha presentado crecimientos anuales hasta el año 2011, siendo el 2009 el más representativo con un crecimiento del $12,07 \%$ con 38.835 permisos. A partir del 2012 hasta el 2014 se evidencia una tendencia decreciente, es así, que en el año 2014 la disminución es más significativa con 18,53\% respecto al año 2013. A pesar de esta tendencia decreciente en el país, Tungurahua presenta, en el 2014, un incremento de 5,09\%.

\section{Figura 1. Permisos de Construcción en Ecuador y Tungurahua Periodo 2012 - 2014}

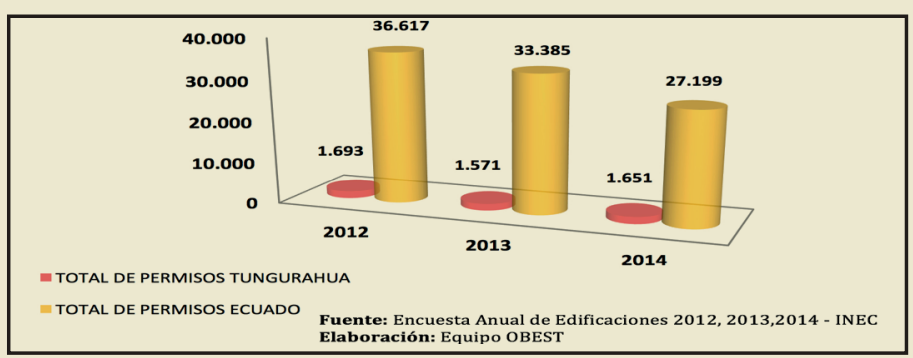

Del total de permisos otorgados en la provincia, en lo referente a tipo de obra el $87,89 \%$ son concedidos para nuevas construcciones con 1.451 permisos, el 11,93\% para ampliación con 197 permisos y para reconstrucción $0,18 \%$, únicamente 3 permisos. En 2014, las nuevas construcciones tienen un incremento mínimo de $2,62 \%$ respecto al 2013 , mientras que en ampliaciones se evidencia un incremento importante de $25,48 \%$.

\section{Figura 2. Permisos de Construcción por tipo de obra en Tungurahua Año 2014}

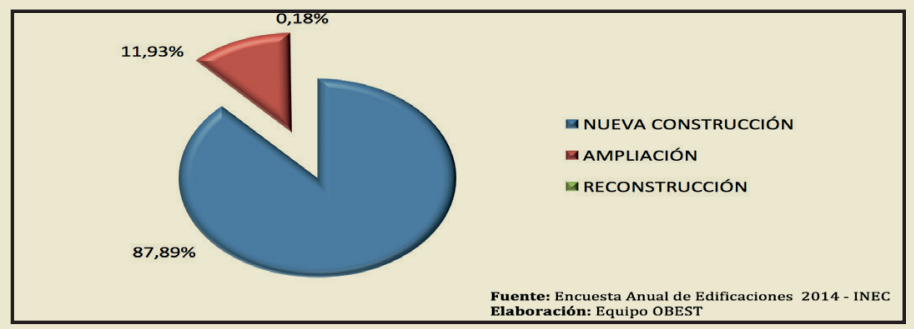

Según el uso de la edificación, en su mayoría los permisos otorgados son para uso residencial con el 83,34\%, no residencial 9,93\% y para uso mixto el 6,72\%. Del total residencial, el 73,62\%, (1.013 permisos) son concedidos para residencia unifamiliar, el 15,26\% para residencia de dos o más familias con 210 permisos y el $11,12 \%$ para tres o más familias con 153 permisos, observando una inclinación significativa por viviendas unifamiliares. La tendencia ha sido creciente en el año 2014 para residencia de una y dos familias con un incremento de $10,47 \%$ y $11,70 \%$ respectivamente, mientras que para residencias de tres o más familias existen una disminución importante de 19,05\%.

\section{Figura 3. Pemisos de Construcción por uso de la edificación en Tungurahua Año 2014}

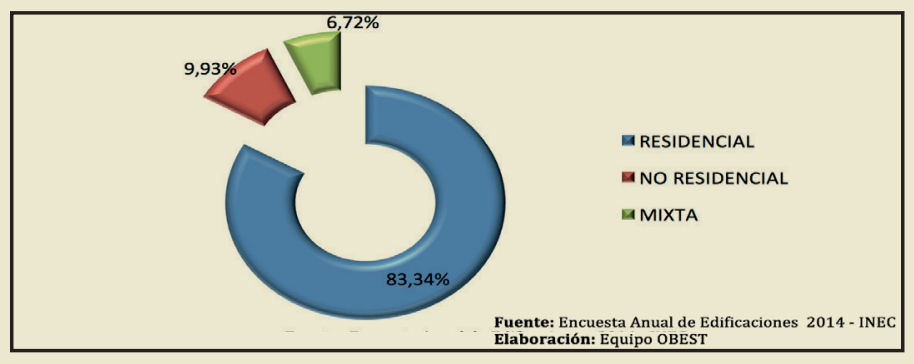

${ }^{1}$ Ingeniera Comercial - Analista de Investigación y Desarrollo del Observatorio Económico y Social de Tungurahua - UTA 
Figura 4. Permisos de Construcción por tipo de residencia en Tungurahua Año 2014

\begin{tabular}{|r|r|r|}
\hline $80 \%$ \\
$70 \%$ \\
$60 \%$ \\
$50 \%$ \\
$40 \%$ \\
$30 \%$ \\
$20 \%$ \\
$10 \%$
\end{tabular}$\quad \begin{gathered}\text { FAMILIA } \\
0 \%\end{gathered}$

Para uso no residencial, es decir, uso comercial e industrial, se ha otorgado el $52,44 \%$ y $10,37 \%$ de permisos respectivamente, la diferencia $37,20 \%$ se distribuye en diferentes propósitos de construcción tales como: edificios administrativos (público), educación particular y pública, cultura, complejos recreacionales, hospitales, clínicas y otros de salud particular y público, transporte y comunicación, iglesias, templos y afines, y otros.

\section{Figura 5. Permisos de Construcción para uso no residencial en Tungurahua} Año 2014

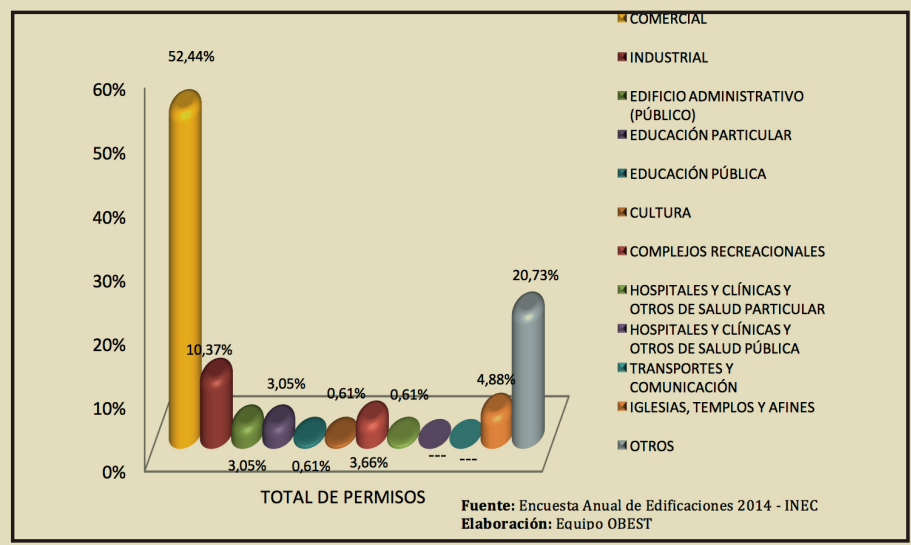

Figura 6. Distribución de los permisos de construcción según fuentes de financiamiento

Año 2014

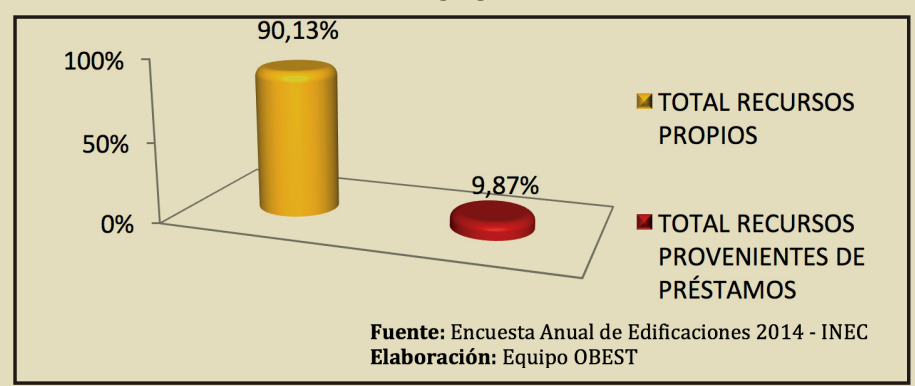

Las fuentes de financiamiento declaradas en los permisos de construcción en el 2014 corresponden al 90,13\% con recursos propios y el $9,87 \%$ con recursos provenientes de préstamos. En lo referente a este último, el 31,90\% declara que su fuente de financiamiento es de préstamos de otros bancos, el 30,06\% de préstamos otorgados por: el Banco del Instituto Ecuatoriano de Seguridad Social - BIESS, Instituto de Seguridad Social de las Fuerzas Armadas del Ecuador - ISSFA o Instituto de Seguridad Social de la Policía Nacional - ISSPOL y el resto en conjunto suman el 38,04\% distribuido en : otros préstamos, préstamos otras financieras, préstamos del Banco de Vivienda - MIDUVI y préstamos de mutualistas.

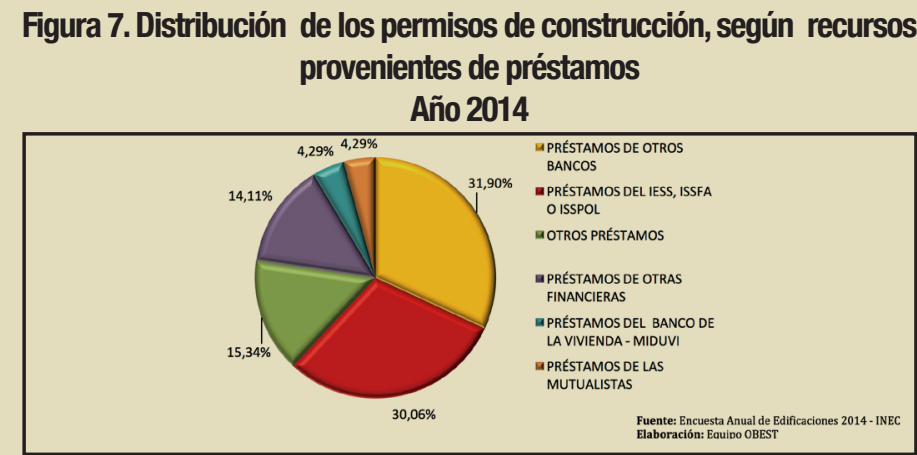

En los materiales predominantes declarados a ser utilizados en las edificaciones se evidencia que en los cimientos existe una preferencia mayoritaria por el hormigón armado con el 78,13\%, solamente un 21,87\% registra otros materiales, tales como: hormigón ciclópeo, pilotes madera, pilotes hormigón y otros. En lo relacionado a la estructura y cubierta predomina la misma tendencia por el hormigón armado con 96,12\% y 90,98\% respectivamente; mientras que en paredes se registra una preferencia por el uso de ladrillo con $77,35 \%$, seguido por bloque con el $22,53 \%$.

Finalmente, en lo referente a los permisos por metro cuadrado - $\mathrm{m}^{2}$, el $75,77 \%$ lo solicitan para construcciones que van a partir de los $200 \mathrm{~m}^{2}$ a $700 \mathrm{~m}^{2}$ y más, y en menor porcentaje lo solicitan para construcciones de menos de $200 \mathrm{~m}^{2}$ con el $24,23 \%$.

\section{Figura 8. Permisos de construcción, según metro cuadrado} Tungurahua 2014

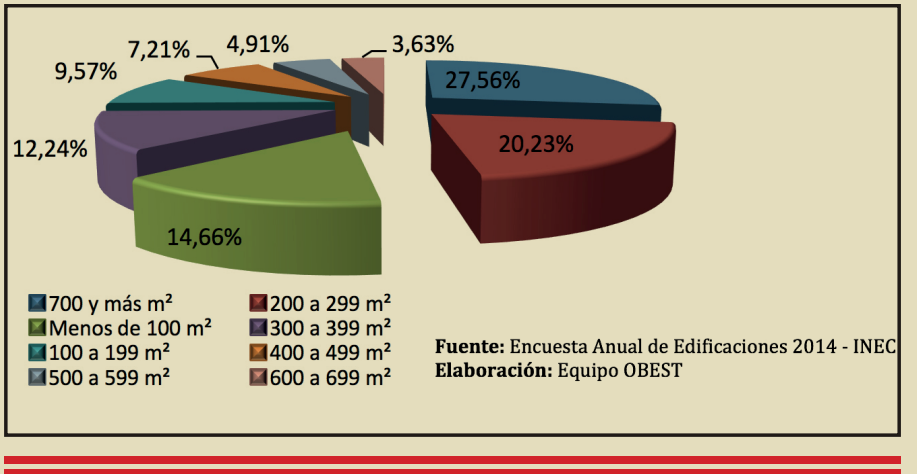

\section{REFERENCIAS}

- GAD Municipal de Ambato. (2005-2009). Plan de Ordenamiento Territorial Ambato 2020. Disponible en: http://gadmatic.ambato. gob.ec/gadmatic/docs/reforma.pdf

-Instituto Nacional de Estadística y Censos. (2012). Encuesta de Edificaciones. Disponible en: http://www.ecuadorencifras.gob.ec// documentos/web-inec/Estadisticas_Economicas/Encuesta_Edificaciones/Publicaciones/Edificaciones_2012.pdf

-Instituto Nacional de Estadística y Censos. 2013. Encuesta de Edificaciones. Disponible en: http://www.ecuadorencifras.gob.ec// documentos/web-inec/Estadisticas_Economicas/Encuesta_Edificaciones/Publicaciones/Edificaciones_2013.pdf

-Instituto Nacional de Estadística y Censos. 2014. Encuesta de Edificaciones. Disponible en: http://www.ecuadorencifras.gob. ec//documentos/web-inec/Estadisticas_Economicas/Encuesta_ Edificaciones/Publicaciones/Edificaciones_2014.pdf 